\title{
Telemedicine Services Contribution to the Sustainable Social Development
}

\author{
Alyona Fechina*, Elena Dvoryadkina, Felix Badaev \\ Ural State University of Economics, Ekaterinburg, Russian Federation \\ ${ }^{*}$ Corresponding author.Email: afechina_1@mail.ru
}

\begin{abstract}
During the research the authors identified the main directions for achieving sustainable development in healthcare. The purpose of the work is to study the telemedicine services contribution to the sustainable social development. A man determined that telemedicine services contributed to the coverage of the population with high-quality medical services at an acceptable cost level, simplified the interaction and communication of health care subjects, supported countries in the fight against global challenges, such as aging of the population, high prevalence of non-communicable diseases, growth of new cases of infectious diseases. The study consists of the function classification of telemedicine services. They are: clinical, communicative, preventive and educational types. The authors revealed the specificity of the telemedicine service from the point of view of the functions assigned to it; and proved the effectiveness of telemedicine services in the implementation of sustainable social development by the example of the countries experience.
\end{abstract}

Keywords: telemedicine services market, sustainable social development, public health.

\section{INTRODUCTION}

According to the generally accepted definition, sustainable development is a development that ensures the satisfaction of modern generation needs and does not affect the ability to meet the needs of future generations [1]. The transition to sustainable development, closely related to technological changes and innovations, creates an alternative model of the economy and sets new priorities in social development. No doubt, achieving sustainability depends on succeeding in a balance between the economic, social and environmental aspects of development. The United Nations defines ensuring a healthy lifestyle and promoting well-being at any age as one of the 17 global goals [2].

By 2030, all countries of the world are to reach the universal coverage of high-quality health services: prevention, diagnosis, treatment, rehabilitation, palliative care. Progress in achieving universal health care coverage is measured not only by the actual coverage of basic health services and the level of social protection of the population, but also by such indicators as quality and safety [3].

The information technologies development contributes to the rapid coverage of high-quality medical services for all residents at an acceptable cost level, simplifies the processes of interaction and communication of all market participants. The telemedicine technologies use in medicine makes it possible to strengthen the healthcare system by providing additional access to medical services in remote regions, conducting long-distance consultations of doctors, determining the need and urgency of hospitalization, repeated consultations of patients, etc.

Telemedicine services are a strictly individualized set of measures involving the information and communication technologies use for the prevention, identification of causes, diagnosis and diseases treatment in order to increase public health in conditions where distance, time and finances are critical factors [4].

\section{MATERIALS AND METHODS}

During the research the authors analyzed the main functions of telemedicine services, determined the its specifics from the point of view of the socio-economic functions assigned to it, summarized the experience of countries in the fight against the global challenges by telemedicine.

Based on the definition, the main goal of telemedicine services is to increase the citizens health. At the same time, being part of the healthcare system, telemedicine 
services solve the following tasks: combating challenges and contributing to solving the problems of the system (qualified personnel shortage, lack of funding, inequality in the medical care availability) (Fig. 1).

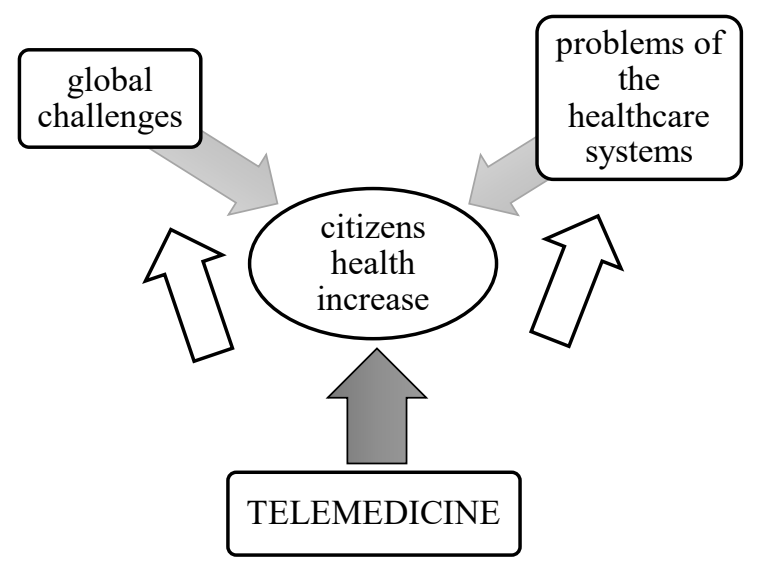

Figure 1 Goals and Objectives of Telemedicine Services.

Despite the huge difference in the level of well-being, economic development and health organization systems, most countries face three main challenges: the aging of the population, the high prevalence of noncommunicable diseases, the growth of new cases of infectious diseases.

\subsection{Population Aging}

In 2018, total government spending on healthcare reached a huge level of $10 \%$ of the global GDP ( $\$ 8.3$ trillion) [5]. The level of health care spending per capita in the world is $\$ 1,110$ and shows a steady growth. The average life expectancy growth of the population is undoubtedly one of the positive results of the world health care development. Over the past 70 years, there have been significant shifts in the life expectancy at birth: from 45 to 73 years [6]. According to the United Nations forecasts by 2100 the average life expectancy in the world will exceed 82 years [7]. The reverse side of the global increase in life expectancy in the absence of positive dynamics of the birth rate is the aging of the population. Over the past 56 years, the share of the population aged 65 years and older has increased by $3.5 \%$, reaching a value of $8.7 \%$ of the total population of the Earth [6].

\subsection{Growth of Non-Communicable Diseases}

Non-communicable diseases (NCDs) are the most common cause of death ( $71 \%$ of all deaths) and disability in the world. Every year, 15 million people of working age die from NCDs [8]. Persons with a low social status are more susceptible to NCDs. Together with poverty, this category of diseases creates a vicious circle: poverty increases behavioral risk factors that lead to non- communicable diseases, and the resulting NCDs can contribute to a further decline in the financial situation. Economic analysis shows that a $10 \%$ increase in NCDs leads to a decrease in annual economic growth by $0.5 \%$. According to the experts, the total economic losses caused by non-communicable diseases will reach $\$ 7$ trillion in low- and middle-income countries for the period from 2011 to 2025, under a stable scenario. [9] Economic losses far exceed the costs of taking highly effective measures to reduce the spread of noncommunicable diseases ( $\$ 11.2$ billion per year).

\subsection{Prevalence of New Infectious Diseases}

Every year, there are from 30 to 40 million cases of infectious diseases (caused by the penetration of pathogenic microorganisms and viruses into the body) in the world [10]. Socio-economic, environmental, behavioral factors, as well as active migration flows contribute to and increase the spread of infectious diseases. In addition to well-studied pathogens such as plague, tuberculosis and malaria, new pathogens such as human immunodeficiency virus (HIV), Ebola, influenza A/H1N1 and H5N1, COVID-2019, etc., which have mutated or passed from animals, are challenging national health systems. Mortality due to infectious diseases is much lower than from non-communicable diseases. Nevertheless, temporary disability and invalidity, the causes of which are infectious diseases, lead to significant economic losses. According to experts, the losses from lost profits and the costs inherent in increasing the mortality rate exclusively from the influenza pandemic annually amount to about $\$ 500$ billion per year $(0.6 \%$ of the world GDP) $[6 ; 11]$. Even with the relatively limited impact of an outbreak on the citizens health, its economic consequences can quickly increase. For example, in 2013-2014, during the Ebola outbreak in West Africa, the GDP growth rate of Liberia decreased by $8 \%$, even despite the overall decrease in the death rate in the country [11]. According to the Ministry of Foreign Affairs of the Russian Federation, the losses of the world economy from the COVID-19 pandemic exceeded $\$ 3.5$ trillion, which is twice as much as the damage from the economic crisis of 2008 [12].

\subsection{Problems of National Health Systems}

Moreover, national governments are to solve the problems of national health systems. Thus, according to the World Health Organization, in order to fully meet the needs of citizens for medical care, health care costs should be at least $12 \%$ of GDP in accordance with the current level of introduction of medical technologies. The fundamental needs of the population with an acceptable level of quality can be met at a spending level of at least $6-8 \%$ of GDP. The critical threshold for financing health care is defined by WHO at the level of 5\% of GDP [13]. At the same time, the greater the country's per capita 
income and the volume of total health care expenditures, the higher the country is ranked in the human development index. In most countries with the highest actual values of the human development index, health spending is approaching the level of the WHO target indicator and a man has already practiced an individualized approach in identifying, forming and meeting the long-term demand of patients.

At the same time, researchers in the field of medical development recognize the paradox of innovations in healthcare: on the one hand, innovative high-tech solutions can improve the medical services quality and the ability of the healthcare system to meet the needs of the population, and on the other hand, they determine the healthcare costs growth [14]. In this regard, the problem of accessibility of innovative medical services for the population is of great importance.

During Russian healthcare reforms (2010s), there was an increase in the disparity in access to medical care. An acute shortage of personnel does not enable to fully provide qualified medical care to the population. According to the World Health Organization, the global shortage of doctors, nurses and midwives may reach 9.9 million people by 2030 [8]. Already today, the shortage of only junior medical personnel is about 5.9 million people. Thus, the number of medical workers is already insufficient to meet the needs of the population in medical care. The most acute problem of the shortage of nursing staff is in Africa, South-East Asia, as well as in a number of Latin American countries. It is well known that the development of medical technologies is much faster than the introduction of accumulated knowledge in the field of healthcare into widespread practice in territories remote from the central regions, which sometimes takes more than a decade [15]. Due to the telemedicine new technologies introduced in leading medical organizations become available.

Regional and territorial differences prevent equal access of the population to medical services. Often, the only permanent communication in remote areas is by air, but the costs of air transportation are at a high level and are inaccessible to the medium and low-income countries.

\section{RESULTS AND DISCUSSION}

The presence of these global challenges and health problems necessitate the search for alternative solutions. Telemedicine proves its effectiveness in practice. The specifics of a telemedicine service can be determined from the point of view of the functions assigned to it, classified by the author, as shown in Table 1 .

The social significance of telemedicine lies in its effectiveness in the fight against the main challenges facing the healthcare system. Thus, telemedicine has proven itself in monitoring the physiological parameters of patients, such as blood pressure, heart rate, blood glucose concentration, etc. [16], including in everyday home settings. A large-scale study in the field of telemedicine among 6,000 patients, of which 3,000 had non-communicable diseases of the cardiovascular system, diabetes or bronchitis, conducted by the UK Ministry of Health showed incredible results: emergency hospitalization decreased by $20 \%$, and mortality - by $45 \%$ [17]. American scientists have proven the effectiveness of the telemedicine use in practice: face-toface visits to medical institutions by patients with congestive heart failure decreased by $80 \%$, and visit duration - by $300 \%$ compared to other patients with a similar diagnosis [18].

Telemedicine helps to provide elderly and disabled people with high-quality outpatient care. Telenursing is effective when a decrease in the physiological reserve of the body, age-related changes on the part of organs and systems, non-communicable diseases, an increased risk of adverse reactions due to a large number of medications taken, a decrease in social status affect the treatment features of elderly and senile patients [19]. Technological innovations introduced in the social sphere make it possible to provide remote social support services for the elderly and disabled people more specifically, dispatching services for the deaf and hard of hearing via video communication.

Table 1. Classification of the Telemedicine Services Functions.

\begin{tabular}{|c|c|c|c|}
\hline Clinical & Communicative & Preventive & Educational \\
\hline $\begin{array}{l}\text { Provision of telemedicine } \\
\text { services: telemedicine } \\
\text { consultations, telemonitoring, } \\
\text { telenursing }\end{array}$ & $\begin{array}{l}\text { Timely dissemination of verified } \\
\text { information about health and } \\
\text { organization of medical service } \\
\text { provision }\end{array}$ & $\begin{array}{l}\text { Remote collection of } \\
\text { health information }\end{array}$ & \multirow[t]{2}{*}{$\begin{array}{l}\text { Quality improvement of } \\
\text { continuing medical education }\end{array}$} \\
\hline $\begin{array}{l}\text { Support of the treatment and } \\
\text { diagnostic process }\end{array}$ & $\begin{array}{c}\text { Effective intercollegiate } \\
\text { communication for medical } \\
\text { professionals }\end{array}$ & $\begin{array}{l}\text { Monitoring of the } \\
\text { epidemiological } \\
\text { situation }\end{array}$ & \\
\hline $\begin{array}{c}\text { Quality assessment of } \\
\text { medical care }\end{array}$ & \multirow[t]{2}{*}{$\begin{array}{l}\text { Improvement of the medical } \\
\text { services availability }\end{array}$} & \multirow[t]{2}{*}{$\begin{array}{l}\text { Targeted work with } \\
\text { risk groups }\end{array}$} & \multirow{2}{*}{$\begin{array}{l}\text { Training of various groups of } \\
\text { the population on healthy } \\
\text { lifestyle, prevention, medical } \\
\text { examination }\end{array}$} \\
\hline $\begin{array}{l}\text { Quality improvement of } \\
\text { diagnostics, secondary and } \\
\text { tertiary prevention }\end{array}$ & & & \\
\hline
\end{tabular}


The coronavirus pandemic, which caused the need for a significant reduction in social contacts, has demonstrated the demand for online medical consultations. The need for the development of remote services has become obvious. During this period, thanks to state support measures, remote communication between a patient and a doctor became widespread in the world, which became an effective solution for scaling the healthcare system under high load conditions [21]. Thus, a man used video consultations through telesystems to determine the need for hospitalization and the amount of care provided for COVID-19 during the coronavirus pandemic.

The medical community agrees that when considering the issue of financing health care, medical efficiency is to be in the first place and economic efficiency is only in the second. Nevertheless, in most cases, telemedicine technologies can reduce costs in healthcare. The analysis of the efficiency of this industry is usually carried out according to the "price-efficiency" model, which assumes the calculation of the economic feasibility of the project, where the price is expressed in monetary indicators, and the efficiency - in qualitative ones. Most of the conducted studies recorded a reduction in costs in the case of telemedicine compared to traditional methods in the amount of $2-73 \%$ [22]. Patients noted that with the help of telemedicine, health services are becoming more accessible. Timely consultations on treatment, care and correction of medical prescriptions can improve the quality of services provided. To achieve a high economic efficiency level of telemedicine, the frequency of telemedicine equipment use is important. Therefore, the number of telemedicine consultations that allowed avoiding face-to-face ones is of great importance. In addition, an important factor is a complete reduction in the cost of traveling from home to a medical institution and indirect costs associated with weaning from home / work, etc.

Telemedicine helps to reduce geographical inequality and improve the efficiency of providing medical services to patients from remote areas [23]. It has proven itself in emergency situations (the earthquake in Armenia in 1988, the fire in the nightclub "Chromaya Loschad" in 2009, the flood in the Far East in 2013, etc.) [24], as well as for medical support of extreme sports: mountaineering expeditions to Mount Everest and Antarctica, long swims on the Amazon River [25].

Telemedicine contributes to the educational process continuity, information support for events in the field of healthcare organization, and clinical audit. The problem of the medical personnel shortage in the field can be solved by creating regional expert centers. Medical professionals who need the advice of narrow high-level specialists can request the colleagues expertise on the obtained research results. For example, with the remote support of an ultrasound diagnostics doctor, a district therapist or a paramedic can conduct an ultrasound examination on the road [26].

Greater patient satisfaction is due to the shift towards a value-based approach and consumerization of medicine: remote provision of medical services reduces waiting times, as well as costs. According to the survey results, the level of satisfaction with the telemedicine services provided is comparable to a full-time visit to a healthcare institution. For example, studies on the demand quality in teleglaucoma centers demonstrate a high level of satisfaction with services: $90-98 \%$ [27].

\section{CONCLUSION}

1. Ensuring a healthy lifestyle and promoting wellbeing for all inhabitants of the planet at any age is the key to sustainable social development. The transformation of the medical services market, accompanied by permanent changes in the processes of providing medical care, opens up opportunities for reducing costs and significantly increasing the availability of high-quality services. In a post-industrial society, the leading importance is given to time, the speed of communication and comfortable conditions not only for consumers, but also for healthcare workers.

2. Knowledge in the field of healthcare is deepening every year. It is impossible for general physicians to keep track of such a large amount of information. If it is necessary to detail medical knowledge, it is justified to seek advice from narrow specialists. Today, the development of communication means allows receiving such consultations with the help of telemedicine technologies.

3. Telemedicine requires quite high costs for its organization. However, telemedicine services contribute to increasing the availability of quality services. The economic effect is achieved through the treatment of diseases in the early stages, reducing the chronicity and prevention of diseases, reducing the negative consequences of NCDs.

4. In the current global situation, telemedicine, from the point of view of the socio-economic functions assigned to it, has demonstrated its effectiveness in expanding the availability of medical care, which, in turn, leads to a reduction in health care costs. The study of economic issues of telemedicine is of scientific interest and requires further study.

\section{REFERENCES}

[1] Report of the World Commission on Environment and Development: "Our common future", World Commission on Environment and Development. UN, 1987, p. 374. 
[2] Official Cite of the United Nations. https://www.un.org/.

[3] Delivering Quality Health Services: a Global Imperative for Universal Health Coverage, World Health Organization, Organization of Economic Cooperation and Development and International Bank for Reconstruction and Development. World Bank, 2019, p. 106.

[4] E.B. Dvoryadkina, A.O. Fechina, Defining "Telemedicine Services" in the Context of LargeScale Digitalization. In: 1st International Conference on Environmental Sustainability Management and Green Technologies (ESMGT 2021), 2021. DOI: https://doi.org/10.1051/e3sconf/ 202129608021.

[5] Global Spending on Health: Weathering the storm. World Health Organization, 2020, p. 2.

[6] Official Cite of the World Bank. http://data.worldbank.org.

[7] Official Cite of the United Nations Data Retrieval System. http://data.un.org/.

[8] Official Cite of the World Health Organization. http://www.who.int/.

[9] Global status report on noncommunicable diseases 2014. World Health Organization, 2014, p. 280.

[10] Vaccination against Infectious Diseases. Dossier, TASS News Agency, 2016. https://tass.ru/info/690191.

[11] D. I. Bloom, D. Cadarette, H. P. Seville, Epidemics and Economics. Quarterly Journal of the International Monetary Fund "Finance and Development", 55(2) (2018) p. 46.

[12] The Russian Foreign Ministry Estimated the Global Losses from the Pandemic Twice as Much as from the $2008 \quad$ Crisis. Kommersant. https://www.kommersant.ru/doc/4743557.

[13] WHO Global Health Expenditure Atlas. World Health Organisation, 2014, pp. 3-4.

[14] L. D. Popovich, I. M. Sheiman, S. V. Shishkin, etc., Healthcare Modernization: New Situations and New Tasks, Moscow, Publishing House "Delo" of the RANEPA, 2014, pp. 156-169.

[15] M. B. Kolesnichenko, Social Aspects of the Telemedicine Introduction, Modern Society: Questions of Theory, Methodology. Methods of Social Research, 1 (2017) pp. 146-151.

[16] J. Stoffer, The Promise of eHealth for Primary Care: Opportunities for Service Delivery, Patient-Doctor Communication, Self-Management, Shared
Decision Making and Research. European Journal of General Practice, 24(1) (2018) pp. 146-148.

[17] The UK: Your Partner for Digital Health Solutions, UK Government, 2016. https://www.gov.uk/govern ment/publications/digital-health-working-inpartnership/the-uk-pioneering-digital-healthsolutions.

[18] A.F. Jerant, R. Azari, C. Martinez, T.S. Nesbitt, A Randomized Trial of Telenursing to Reduce Hospitalization for Heart Failure: Patient-Centered Outcomes and Nursing Indicators. Home Health Care Serv. Q., 22(1) (2003) pp. 1-20. DOI: https://doi.org/10.1300/J027v22n01_01.

[19] M. Koivunen, K. Saranto, Nursing Professionals' Experiences of the Facilitators and Barriers to the Use of Telehealth Applications: a Systematic Review of Qualitative Studies. Scand J. Caring Sci., 32(1) (2018) pp. 24-44. DOI: https://doi.org/10.1111/scs.12445.

[20] K. Lam, A.D. Lu, Y. Shi, et al., Assessing Telemedicine Unreadiness Among Older Adults in the United States During the COVID-19 Pandemic. JAMA Intern. Med., 180(10) (2020) pp. 1389-1391. DOI: https://doi.org/10.1001/jamainternmed.2020. 2671.

[21] J.E. Hollander, B.G. Carr, Virtually Perfect? Telemedicine for Covid-19. The New England Journal of Medicine, 382 (2020) pp. 1679-1681. DOI: https://doi.org/10.1056/NEJMp2003539.

[22] H. Van Os-Medendorp, H. Koffi jberg, P.C. Elandde Kok, M. S. de BruinWeller, S.G. Pasmans, et al., E-health in Caring for Patients with Atopic Dermatitis: a Randomized Controlled CostEffectiveness Study of Internet-Guided Monitoring and Online Self-Management Training. Br. J. Dermatol, 66(5) (2012) pp. 1060-1068. DOI: https://doi.org/10.1186/s12912-020-00494-y.

[23] N. A. Voskolovich, Management of Accessibility and Quality of Medical Care to the Population. Municipality: Economics and Management, 1(22) (2018) pp. 18-24.

[24] N. M. Vasilyeva, T. M. Kuznetsova, O. M. Novikova, S. G. Salivon, O. I. Masleeva, O. I. Mehedova, S. V. Koreshkova. Information collection "Medicine of Catastrophes. Service of Disaster Medicine", FSBI All-Russian Center for Disaster Medicine "Zascshita" of the Ministry of Health of the Russian Federation, Moscow, 2019.

[25] Yu. I. Senkevich, Development of Information Technologies for Medical Support of Polar 
Expeditions. Ukr. Z H. telemed. with. telemat, 2(1) (2004) pp. 22-28.

[26] A. Shepeleva, Diagnosis Online. Rossiyskaya Gazeta-Federal, 264(8022) (2019) p. 9.

[27] J.H. Court, M.W. Austin, Virtual Glaucoma Clinics: Patient Acceptance and Quality of Patient Education Compared to Standard Clinics. Clin Ophthalmol, 9 (2015) pp. 745- 749. DOI: https://doi.org/10.2147/ OPTH.S75000. 